\title{
Effect of Preparation Condition on the Performance of MoVTeNbO Cata- lyst Materials for Selective Oxidation of Propane into Acrylic Acid
}

\author{
Wei Zheng ${ }^{*}, 1,2$, Zhenxing $\mathrm{Yu}^{2}$, Yuhang Zhang ${ }^{2}$, Hongying $\mathrm{Fu}^{2}$, Xiaoli Zhang ${ }^{2}$, Ping Zhang ${ }^{2}$, \\ Qiquan $\mathrm{Sun}^{2}$ and Xinguo $\mathrm{Hu}^{1}$ \\ ${ }^{I}$ School of Municipal and Environmental Engineering, Harbin Institute of Technology, Harbin 150001, China \\ ${ }^{2}$ Da qing Nanyuan Group Co., Ltd, .Da Qing 163453, China
}

\begin{abstract}
The effects of chemical composition and preparation conditions, especially calcination atmosphere, water content and oxygen content on the catalytic performances of MoVTeNbO mixed oxide catalyst system for the selective oxidation of propane to acrylic acid have been investigated and discussed. Among the catalysts studied, the $\mathrm{Mo}_{1.0} \mathrm{~V}_{0.3} \mathrm{Te}_{0.23} \mathrm{Nb}_{0.12} \mathrm{O}$ catalyst calcined in inert atmosphere under a temperature of $600^{\circ} \mathrm{C}$ showed the best performance in terms of propane conversion and selectivity to acrylic acid. The results revealed that proper chemical composition, calcination atmosphere, water content and oxygen content affected greatly the catalysts in many ways including structure, chemical composition, which are related to their catalytic performances, the $78 \%$ propane conversion and $61 \%$ one-pass yield to acrylic acid can be achieved at the same time.
\end{abstract}

Keywords: Propane oxidation, selective oxidation, acrylic acid, catalysts preparation.

\section{INTRODUCTION}

Since the last decade, there has been a great interest in the development of highly active and selective catalysts for selective oxidation of light alkanes due to their potential application as a source of cheap raw materials in the petroleum and petrochemical industries [1-5]. Selective oxidation of propane is highly attractive because it would bypass the energy intensive endothermic steam cracking or dehydrogenation reactions currently employed to manufacture olefin intermediates from natural gas and petroleum feedstocks for subsequent oxidation. Catalytic selective oxidation of propane is motivated by both the potential economic and environmental advantages. It has recently attracted great attention in both academia and industry. Up to now, heteropolyacids and their derived salts [6], vanadyl pyrophosphate [7] and mixed metal oxides catalysts [8], have been studied for the acrylic acid production from propane. The most promising mixed metal oxide for propane selective oxidation is the bulk mixed MoVTeNbO system which was disclosed in recent years as highly active and selective for the ammoxidation of propane to acrylonitrile [9] and the propane oxidation to acrylic acid [10-16].

Xinlin reported bulk mixed MoVTeNbO system, which exhibited a $48 \%$ acrylic acid yield and $63.4 \%$ propane conversion under a reaction temperature of $380^{\circ} \mathrm{C}$ [17]. Despite the promise of the results obtained, few papers have reported about the fundamental information (preparation parameters, reaction conditions and catalytic properties of this mixed metal oxide system). The information is very important for the development of this promising catalytic system for selective propane oxidation. Not only the composition of the

*Address correspondence to this author at the School of Municipal and Environmental Engineering, Harbin Institute of Technology, Harbin 150001, China; E-maill: zhengV்8V்wei@163.com oxide elements, but also some specific structures of the resulting complex oxides are closely related to their catalytic performance. So, the external reaction conditions for this system of catalysts were investigated in an effort to understand the effects on the catalyst structure and the performance under the optimized reaction conditions. In this paper, the effects of metal atomic ratio, calcination temperatures, calcination atmosphere, water content and oxygen content on the catalytic performance were studied for the selective oxidation of propane into acrylic acid.

\section{EXPERIMENTAL}

\subsection{Catalyst Preparation}

Used as source chemicals for the precursor compounds of the oxides are $\mathrm{NH}_{4} \mathrm{VO}_{3}$ (ammonium metavanadate) for $\mathrm{V}$, $\left(\mathrm{NH}_{4}\right)_{6} \mathrm{Mo}_{7} \mathrm{O}_{24} \cdot 4 \mathrm{H}_{2} \mathrm{O}$ (ammonium heptamolybdate) for $\mathrm{Mo}$, $\mathrm{Te}(\mathrm{OH})_{6}$ (telluric acid) for Te, respectively and all were purchased from Aldrich. The precursor compound as the source for $\mathrm{Nb}$ was niobium oxalate, which was purchased from the Reference Metals Company. Dissolving the desired amounts of ammonium metavanadate, ammonium heptamolybdate, and telluric acid in deionized water and stirred at $80^{\circ} \mathrm{C}$ for $1.0 \mathrm{~h}$ in a flask resulted in a uniform aqueous solution. Cooling the solution to $40^{\circ} \mathrm{C}$, and then an aqueous solution of niobium oxalate having the desired niobium concentration was mixed to result in a slurry. The water of the slurry was removed via a rotavapor with a warm water bath at $60^{\circ} \mathrm{C}$ at a reduced pressure of $10-40 \mathrm{mmHg}$ to obtain a dry powder precursor. The catalyst powder precursor was calcined in a range $400-750^{\circ} \mathrm{C}$ for $4.0 \mathrm{~h}$ with a steady nitrogen stream in a covered tubular furnace so as to prevent the entry of air into the flask. The furnace had previously been heated to $200^{\circ} \mathrm{C}$ at a rate of $2^{\circ} \mathrm{C} / \mathrm{min}$ and held at that temperature for $1.0 \mathrm{~h}$, then ramped to $400-750^{\circ} \mathrm{C}$ at a rate of $2^{\circ} \mathrm{C} / \mathrm{min}$ and held at that temperature for $2.0 \mathrm{~h}$. After being cooled to room tem- 
perature, the resulting mixed metal oxide catalyst was obtained. Then the material was ground, pressed and sieved to 10-20 mesh sized granules. The granules were directly used for the evaluation of vapour phase propane selective oxidation in a micro-reactor.

\subsection{Catalyst Evaluation}

The catalytic performance of the mixed metal oxide catalysts was evaluated for the selective oxidation of propane to acrylic acid in a continuous flow fixed bed micro-reactor testing at atmospheric pressure. About $8.0 \mathrm{~g}$ of granules catalyst was packed into a $2 \mathrm{~mm}$ i.d. quartz tube in a programmable oven and heated in a chamber over a temperature of $400^{\circ} \mathrm{C}$.A mixture of propane-oxygen-nitrogen-water vapour was fed in from the top of the reactor. The off-gas was condensed and separated from the liquid phase in several cold traps. Product streams were then analyzed by GC to determine the propane conversion and oxidation product distribution. The carbon balance was always above 95\%.The performance of the catalyst is measured by propane conversion, yields of acrylic acid or other products, and specific selectivity. The selectivity, conversion and yield expressed in molar percentage form were calculated on a base of propane.

\section{RESULTS AND DISCUSSION}

\subsection{The Influence of the Calcination Temperature on Catalytic Performance}

The calcination parameters, such as atmosphere, heating rate or temperature, can affect the resulting catalyst structures, which, in turn, affect the resulting catalytic performance in the selective oxidation of propane to acrylic acid [18]. The discussions here will be limited to only the effects of calcination temperatures. The effect of calcination temperatures on the resulting mixed MoVTeNbO catalyst precursor system was investigated in a range $400-750^{\circ} \mathrm{C}$ under an atmosphere of nitrogen. The catalysts precursor was calcined at different temperature of $400^{\circ} \mathrm{C}, 450^{\circ} \mathrm{C}, 500^{\circ} \mathrm{C}$, $550^{\circ} \mathrm{C}, 600^{\circ} \mathrm{C}, 650^{\circ} \mathrm{C}, 700^{\circ} \mathrm{C}, 750^{\circ} \mathrm{C}$ for 3.0 hours. Results in Table 1 show that the reductions in either propane conversion and/or acrylic acid selectivity are observed even with minor changes in the calcination temperatures. It is clear that the calcination temperatures have strong effects on the products distribution in Table 1. An increase in acrylic acid selectivity was observed on increasing the temperature from 400 to $600^{\circ} \mathrm{C}$. A further increase in temperature from 600 to $750^{\circ} \mathrm{C}$ caused a decrease in the selectivity. It is well known from unsupported MoVTeNb-based catalysts that particular calcination temperatures have a crucial influence on phase composition and reduction degree of metal ions, which are related to the catalytic performance [19-25]. Among the mixed MoVTeNbO system catalysts prepared under different calcination temperatures, it shows the highest propane conversion and acrylic acid selectivity at $600^{\circ} \mathrm{C}$. So, it can be concluded that the catalytic activity for propane oxidation and the selectivity to acrylic acid depend strongly on the calcination temperatures.

\subsection{The Influence of Calcination Atmosphere on Cata- lytic Performance}

Calcination is typically the last step for the preparation of the mixed metal oxide catalyst materials. Many factors in the
Table 1. Effect of Calcination Temperatures on Catalytic Performmance

\begin{tabular}{|c|c|c|c|}
\hline $\begin{array}{c}\text { Calcination } \\
\text { Temperatures } \\
\left({ }^{\circ} \mathbf{C}\right)\end{array}$ & $\begin{array}{c}\text { Acrylic Acid } \\
\text { Selectivity } \\
\text { (\%) }\end{array}$ & $\begin{array}{c}\text { Propane } \\
\text { Conversion } \\
(\%)\end{array}$ & $\begin{array}{l}\text { Acrylic Acid } \\
\text { Yield } \\
(\%)\end{array}$ \\
\hline 400 & 29.2 & 42.7 & 12.5 \\
\hline 450 & 34.3 & 46.3 & 15.9 \\
\hline 500 & 47.0 & 45.6 & 21.4 \\
\hline 550 & 52.3 & 53.9 & 28.2 \\
\hline 600 & 61.0 & 78.1 & 47.6 \\
\hline 650 & 54.1 & 52.3 & 28.2 \\
\hline 700 & 49.2 & 29.6 & 14.6 \\
\hline 750 & 46.0 & 16.4 & 7.5 \\
\hline
\end{tabular}
ity $=1800 \mathrm{~h}^{-1}, T=400^{\circ} \mathrm{C}$. All samples were prepared and tested using the same method and conditions.

calcination step can affect the performance of the resulting catalysts. Two different catalyst precursors $\left(\mathrm{Mo}_{1.0} \mathrm{~V}_{0.3} \mathrm{Te}_{0.23}\right.$ $\mathrm{Nb}_{0.12} \mathrm{O}_{\mathrm{n}}$ and $\mathrm{Mo}_{1.0} \mathrm{~V}_{0.32} \mathrm{Te}_{0.23} \mathrm{Nb}_{0.12} \mathrm{O}_{\mathrm{n}}$ ) were prepared with different metal atomic ratio compositions. Each precursor was subjected to two different calcination atmospheres and flow conditions. The catalytic performances of these catalysts are summarized in Table 2. The effects of oxygen in the calcination atmosphere (inert gases versus air) on the performance of the catalysts made from precursors $\mathrm{Mo}_{1.0} \mathrm{~V}_{0.3}$ $\mathrm{Te}_{0.23} \mathrm{Nb}_{0.12} \mathrm{O}_{\mathrm{n}}$ and $\mathrm{Mo}_{1.0} \mathrm{~V}_{0.32} \mathrm{Te}_{0.23} \mathrm{Nb}_{0.12} \mathrm{O}_{\mathrm{n}}$ were examined.The effects of different inert calcination atmospheres (nitrogen versus argon) were compared.

Table 2 shows that as an inert gas with higher density than the air or the nitrogen, argon offers better blanketing effect than the nitrogen in an open calcination system to prevent air from contacting the catalysts in the bottom of calcination container. In the experimental set-up used in this study, the catalyst precursor was placed in the bottom of a container that has an opening to the atmosphere at the top which serves as the out-flow to prevent pressure buildup.On the other hand, the opening also makes it difficult to expel the air out completely. The use of the argon, which has a higher density than the air, in such a calcination set-up helps to exclude most of the air out, so providing an inert blanket covering the catalyst under calcination. On the whole, one does not expect the nitrogen to achieve the same blanketing effects as does the argon in the open system. Thus, our study leads to the conclusion that calcination under an inert atmosphere is preferred, and the argon is more preferred over the nitrogen.

\subsection{The Influence of the Oxygen Content on Catalytic Performance}

The oxygen-propane ratio in the feed has been varied in the range of $1-5$. The catalytic performance at $400^{\circ} \mathrm{C}$ under different oxygen-propane ratios for the selective propane oxidation to acrylic acid is shown in Fig. (1). Fig. (1) shows the catalytic performance as a faction of oxygen to propane. With oxygen-propane ratio increasing from 1 to 5 , the conversion of propane increases from 30 to $85 \%$. The conver- 
Table 2. Effect of Calcination Atmosphere on Catalytic Performmance

\begin{tabular}{|c|c|c|c|c|}
\hline Precursor Metal Composition & Calcination & Propane Conversion (\%) & Acrylic acid Selectivity (\%) & Acrylic Acid Yield (\%) \\
\hline \multirow{6}{*}{$\mathrm{Mo}_{1.0} \mathrm{~V}_{0.3} \mathrm{Te}_{0.23} \mathrm{Nb}_{0.12} \mathrm{O}_{\mathrm{n}}$} & Argon,non-flow & 78.0 & 61.1 & 47.6 \\
\hline & Nitrogen,non-flow & 67.6 & 53.4 & 36.1 \\
\hline & Air, non-flow & 0 & - & 0 \\
\hline & Argon, flow & 41.0 & 26.2 & 11 \\
\hline & Nitrogen,flow & 32.8 & 23.1 & 7.58 \\
\hline & Air, flow & 0 & - & 0 \\
\hline \multirow{6}{*}{$\mathrm{Mo}_{1.0} \mathrm{~V}_{0.32} \mathrm{Te}_{0.23} \mathrm{Nb}_{0.12} \mathrm{O}_{\mathrm{n}}$} & Argon,non-flow & 53.1 & 47.2 & 24.9 \\
\hline & Nitrogen,non-flow & 43.9 & 37.1 & 16.3 \\
\hline & Air, non-flow & 0 & - & 0 \\
\hline & Argon, flow & 40.6 & 34.2 & 13.9 \\
\hline & Nitrogen,flow & 35.6 & 19.7 & 7.01 \\
\hline & Air, flow & 0 & - & 0 \\
\hline
\end{tabular}

Reaction conditions: $\mathrm{C}_{3} \mathrm{H}_{8}: \mathrm{H}_{2} \mathrm{O}: \mathrm{O}_{2}: \mathrm{N}_{2}=4.4: 15.3: 12.8: 36.9(\mathrm{~mol} / \mathrm{mol})$, space velocity $=1800 \mathrm{~h}^{-1}, T=400^{\circ} \mathrm{C}$.Calcination temperature was $600^{\circ} \mathrm{C}$. All samples were prepared and tested using the same method and conditions.

sion of propane monotonously increases with oxygenpropane ratio. So propane conversion increases with the oxygen-propane ratio increasing. That means higher oxygen concentration is favourable for propane activation. The selectivity to acrylic acid decreases from 61.1 to $29.8 \%$ with oxygen-propane ratio increasing. The gradual decrease in acrylic acid selectivity with increasing oxygen concentration is also likely caused by the acrylic acid and other intermediates, which are prone to be overoxidized to $\mathrm{COx}$ under higher oxygen concentration. Baerns concluded that the concentration of propane in the feed gases influences the surface active sites of the catalyst [26]. Before the catalytic reaction, oxygen and propane were used to activate the newly made catalyst, respectively. The results illustrate that propane maintains the reduced state that is beneficial to the reaction. However, the oxygen-rich condition results in a low conversion of propane though the selectivity of acrylic acid may be higher. It is suggested that the reduced state is responsible for the activity and for the formation of acrylic acid in the propane oxidation.

The partially reduced state is suitable for the oxidation because the reduced state provides not only coordinatively unsaturated Mo or $\mathrm{V}$ for the adsorption or stabilization of intermediate species but also basic lattice oxygen that may only be formed near the reduced Mo or V sites [27]. Apparently, it seems reasonable to restrict the oxygen content in the feed to the lower values of the range investigated so far.

\subsection{The Influence of the Water Content on Catalytic Performance}

The presence of water vapour in the feed had a profound effect on the performance of mixed MoVTeNbO catalyst and the selectivity of propane oxidation to acrylic acid. The catalytic performance of the resulting mixed oxides system is further found to be sensitive to the water content in Fig. (2). The effect of water vapor was studied at $400^{\circ} \mathrm{C}$ employing the mixed MoVTeNbO oxide catalyst and the feed containing propane: oxygen: nitrogen $=4.4: 12.8: 36.9(\mathrm{~mol} \mathrm{\%})$ and

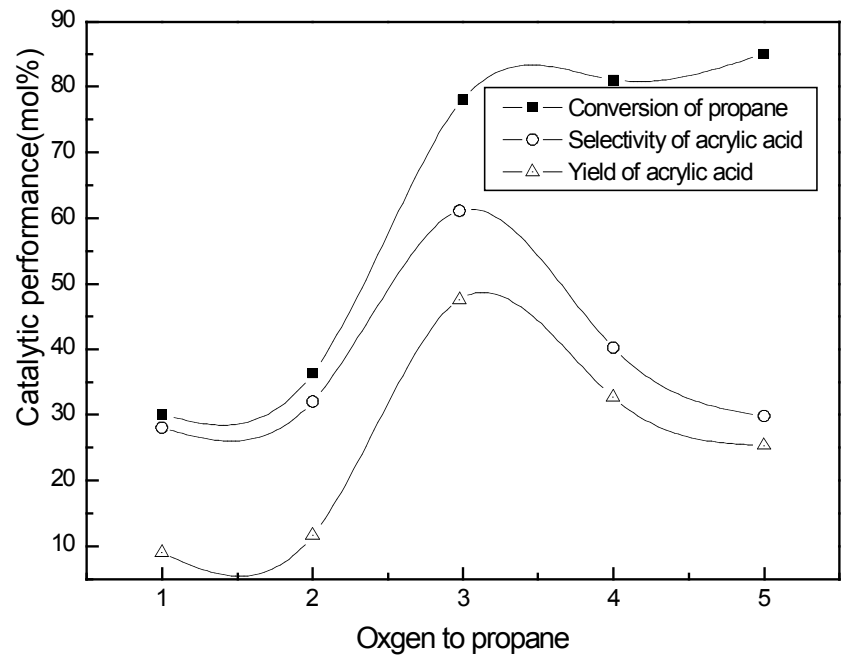

Fig. (1). Effect of oxygen content on catalytic performance. Reaction conditions: $\mathrm{C}_{3} \mathrm{H}_{8}: \mathrm{H}_{2} \mathrm{O}: \mathrm{N}_{2}=4.4: 15.3: 36.9(\mathrm{~mol} / \mathrm{mol})$, space velocity $=800 \mathrm{~h}^{-1}, T=400^{\circ} \mathrm{C}$.

$0-30 \mathrm{~mol} \%$ water vapor as a function of time on stream. The results shown in Fig. (2) indicate that the selectivity to acrylic acid continuously changed as a function of water content in the feed. The activities of catalyst and reactor selectivity to acrylic acid are enhanced by the addition of water vapour. In the absence of water vapour ( $0 \mathrm{~mol} \%)$, an amount of acrylic acid was formed from the oxidation of propane, but the overall yield to acrylic acid was low, mainly due to the low selectivity of acrylic acid. Both the acrylic acid yield and the selectivity to acrylic acid increase with the addition of $15 \%$ water vapour to achieve the maximum. The selectivity to acrylic acid increases rapidly from 6 to $61.1 \%$ when $15 \%$ water vapour was introduced into the feeds, and then decreases from 61.1 to $29 \%$ with the further increasing of the amount of the water vapour. It was found that the excess water vapours (more than $15 \mathrm{~mol} \%$ ) inhibited the reaction leading to acrylic acid probably due to an overadsorption on the catalyst surface. 


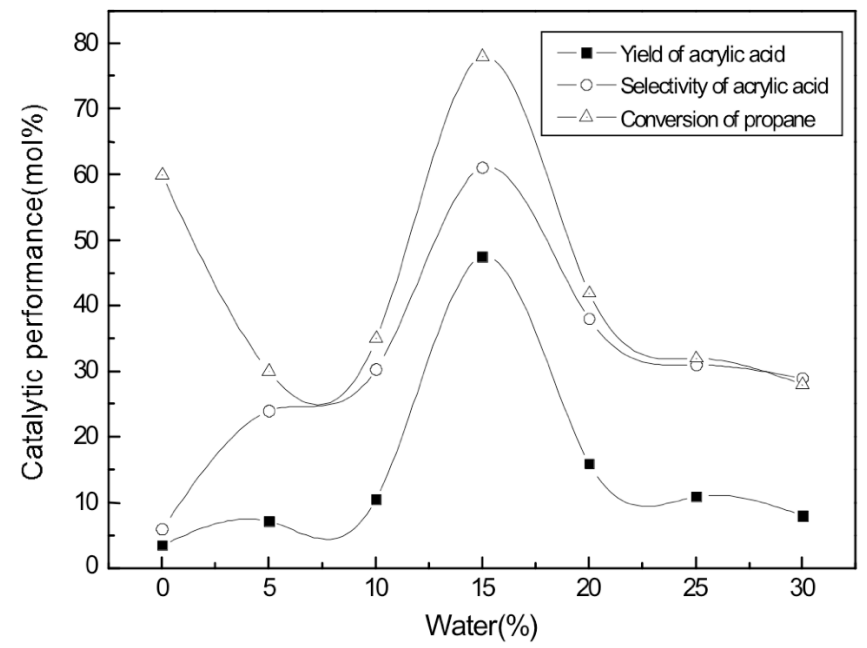

Fig. (2). Effect of water concentration on catalytic performance. Reaction conditions: $\mathrm{C}_{3} \mathrm{H}_{8}: \mathrm{O}_{2}: \mathrm{N}_{2}=4.4: 12.8: 36.9$ (mol/mol), space velocity $=1800 \mathrm{~h}^{-1}, T=400^{\circ} \mathrm{C}$.

These observations indicated that water has two distinct effects in propane oxidation over MoVTeNbO system catalysts. On one hand, the water enhances the rate of propane oxidation to acrylic acid; probably water increases the concentration of hydroxyl groups on the catalyst surface and facilitates the reaction between the adsorbed acryloyl species and hydroxyl groups to form acrylic acid [28]. Water is adsorbed preferentially on Lewis acid sites to give Bronsted acid sites. As a consequence, the strongest adsorbent sites, where carboxylic oxygen bonds to the cation leading to deep oxidation of the reaction intermediates, are removed from catalyst surface [29], thus, enhancing the selectivity of the process and allowing the reoxidation of the catalyst surface [30-32]. On the other hand, water plays a very critical role in determining the desorption of the product, which generally possess an acid function on the catalyst surface to prevent it from overoxidation to $\mathrm{COx}$ in the presence of water vapour.
According to our results, water vapour may also take away the heat produced during the reaction to avoid the hot area on the catalyst surface.

\subsection{The Influence of Metal Molar Ratios on Catalytic Performance}

The catalytic performance of the resulting mixed oxides is further found to be sensitive to the relative metal ratios of the oxides. Results in Table $\mathbf{3}$ show that the preferred metal ratio is around the vicinity of $\mathrm{Mo}_{1.0} \mathrm{~V}_{0.30} \mathrm{Te}_{0.23} \mathrm{Nb}_{0.12} \mathrm{O}_{\mathrm{n}}$. Significant reductions in either propane conversion and/or acrylic acid selectivity are observed even with minor changes in the metal ratio. Drastic reductions in catalytic activity and acrylic acid selectivity are observed when the metal molar ratios, especially those of $\mathrm{Te}, \mathrm{V}$ and $\mathrm{Nb}$ further deviated away from the preferred range. The highest selectivities to acrylic acid were achieved on samples with MoVTeNb molar ratio in Table 3. In this way, it can be noticed that a high yield of acrylic acid of about $47.6 \%$ has been obtained at $400^{\circ} \mathrm{C}$ and a propane conversion of about $78.0 \%$ on this optimal complex metal oxide catalyst.

\section{CONCLUSIONS}

The results of this study reveal that the effectiveness of the MoVTeNbO catalyst system for propane selective oxidation depends not only on the actual catalyst composition, but also largely on the preparation methods and the conditions used.The catalytic performance of propane selective oxidation to acrylic acid is greatly influenced by the reaction conditions. The effect of water vapour on the selectivity of propane oxidation to acrylic acid is important. Both the catalytic activity for propane conversion and the selectivity to acrylic acid seems to be dramatically affected by the water vapour.The main role of steam is to enhance the desorption of acrylic acid from the catalyst surface to prevent it from being overoxidized to catalyst under the optimized reaction conditions was examined. The calcination temperature and calcination atmosphere can affect the resulting catalyst structures,

Table 3. Effect of Calcination Temperatures on Catalytic Performmance

\begin{tabular}{|c|c|c|c|}
\hline Different Metal Molar Ratios Catalysts & Propane Conversion (\%) & Acrylic Acid Selectivity (\%) & Acrylic Acid Yield (\%) \\
\hline $\mathrm{Mo}_{1.0} \mathrm{~V}_{0.5} \mathrm{Te}_{0.3} \mathrm{Nb}_{0.15} \mathrm{O}_{\mathrm{n}}$ & 18.12 & 12.04 & 2.18 \\
\hline $\mathrm{Mo}_{1.0} \mathrm{~V}_{0.3} \mathrm{Te}_{0.24} \mathrm{Nb}_{0.14} \mathrm{O}_{\mathrm{n}}$ & 23.61 & 18.67 & 4.41 \\
\hline $\mathrm{Mo}_{1.0} \mathrm{~V}_{0.3} \mathrm{Te}_{0.23} \mathrm{Nb}_{0.13} \mathrm{O}_{\mathrm{n}}$ & 56.94 & 40.65 & 23.1 \\
\hline $\mathrm{Mo}_{1.0} \mathrm{~V}_{0.31} \mathrm{Te}_{0.23} \mathrm{Nb}_{0.12} \mathrm{O}_{\mathrm{n}}$ & 61.2 & 49.3 & 30.2 \\
\hline $\mathrm{Mo}_{1.0} \mathrm{~V}_{0.32} \mathrm{Te}_{0.23} \mathrm{Nb}_{0.12} \mathrm{O}_{\mathrm{n}}$ & 53.1 & 47.2 & 24.9 \\
\hline $\mathrm{Mo}_{1.0} \mathrm{~V}_{0.33} \mathrm{Te}_{0.23} \mathrm{Nb}_{0.12} \mathrm{O}_{\mathrm{n}}$ & 28.84 & 31.12 & 8.98 \\
\hline $\mathrm{Mo}_{1.0} \mathrm{~V}_{0.31} \mathrm{Te}_{0.5} \mathrm{Nb}_{0.12} \mathrm{O}_{\mathrm{n}}$ & 19.52 & 38.39 & 7.49 \\
\hline
\end{tabular}

Reaction conditions: $\mathrm{C}_{3} \mathrm{H}_{8}: \mathrm{H}_{2} \mathrm{O}: \mathrm{O}_{2}: \mathrm{N}_{2}=4.4: 15.3: 12.8: 36.9$ (mol/mol), space velocity $=1800 \mathrm{~h}^{-1}, T=400^{\circ} \mathrm{C}$. Calcination temperature was $600{ }^{\circ} \mathrm{C}$. All samples were prepared and tested using the same method and conditions. 
which, in turn, affect the resulting catalytic performance in the selective oxidation of propane to acrylic acid. Research in exploring an optimal ratio of metal offerred a good opportunity to further improve the effectiveness of MoVTeNb complex oxides as catalysts for propane selective oxidation to acrylic acid.

\section{ACKNOWLEDGEMENTS}

All experiments in the studies were conducted in Da Qing Oil-field Triumph Group R\&D Centre. The authors gratefully acknowledge financial and experimental support from the Da Qing Petroleum Co., Ltd.

\section{REFERENCES}

[1] Baichun Z, Hongbo L, Weishen Y, Liwu L. Effects of reaction conditions on the selective oxidation of propane to acrylic acid on Mo-V-Te-Nb oxides. Catal Today 2004; 93-95: 229-34.

[2] Vadim V, Rishabh B, Jamal N, Vijay K, Rajiv S. Bulk mixed Mo$\mathrm{V}-\mathrm{Te}-\mathrm{O}$ catalysts for propane oxidation to acrylic acid. Appl Catal A 2004; 274: 123-32.

[3] Takashi U. Activation of propane and butanes over niobium- and tantalum-based oxide catalysts. Catal Today 2003; 78: 79-84.

[4] Beato P, Blume A, Girgsdies F, et al. Analysis of structural transformations during the synthesis of a MoVTeNb mixed oxide catalyst. Appl Catal A 2006; 307: 137-47.

[5] Jamal N, Al-Saeedi V, Vasudevan V. Model bulk Mo-V-Te-O catalysts for selective oxidation of propane to acrylic acid. Catal Commun 2003; 4: 537-42.

[6] Wataru U, Damien V, Tomokazu K. Crystalline Mo-V-O based complex oxides as selective oxidation catalysts of propane. Catal Today 2005; 99: 43-9.

[7] Wang D, Kung H, Barteau M. Identification of vanadium species involved in sequential redox operation of VPO catalysts. Appl Catal A Gen 2000; 201: 203-13.

[8] Jamal N, Al-Saeedi V, Guliants. High-throughput experimentation in multicomponent bulk mixed metal oxides: $\mathrm{Mo}-\mathrm{V}-\mathrm{Sb}-\mathrm{Nb}-\mathrm{O}$ system for selective oxidation of propane to acrylic acid. Appl Catal A 2002; 237: 111-20.

[9] Shinji I, Satit P, Shin-ichi K, Tadashi H, Atsushi S. Involvement of active sites of promoted vanadyl pyrophosphate in selective oxidation of propane. J Catal 2005; 236: 304-12.

[10] Botella P, López Nieto J, Solsona B, Mifsud A, Marquez F. The Preparation, Characterization, and Catalytic Behavior of MoVTeNbO Catalysts Prepared by Hydrothermal Synthesis. J Catal 2002; 209: 445-55.

[11] Botella P, García-González E, López Nieto J, González-Calbet J. MoVTeNbO multifunctional catalysts: Correlation between constituent crystalline phases and catalytic performance. Solid State Sci 2005; 7: 507-19.

[12] Johan H, Robert K, Andersson A. Catalytic behaviour of M1, M2, and M1/M2 physical mixtures of the Mo-V-Nb-Te-oxide system in propane and propene ammoxidation. Appl Catal A Gen 2004; 270: 121-34.

[13] Hanpei Y, Yining F, Junming W, Yi C. Structure and properties of $\mathrm{BiCeVMoO}$ mixed metal oxides catalysts for selective oxidation of propane. J Mol Catal A Chem 2005; 227: 279-83.

[14] Takashi U, Kazunori O, Atsushi K, Masakatsu H. Ammoxidation of propane over Mo-V-Nb-Te mixed oxide catalysts. Studies Surf Sci Catal 1997; 112: 473-80.

[15] Botella P, López Nieto J, Solsona B. Selective oxidation of propene to acrolein on Mo-Te mixed oxides catalysts prepared from ammonium telluromolybdates. J Mol Catal A Chem 2002; 184: 335-47.
[16] Botella P, López Nieto J, Solsona B, Solsona A, Mifsud F. The Preparation, Characterization, and Catalytic Behavior of MoVTeNbO Catalysts Prepared by Hydrothermal Synthesis. J Catal 2002; 209: 445-55.

[17] Xinlin T, Naomasa F, Yuuichi S, Mamoru T, Hiroshi N. A new approach to the preparation of MoVNbTe mixed oxide catalysts for the oxidation of propane to acrylic acid. Catal Today 2006; 117: 259-64.

[18] Manhua L. Complex metal oxide catalysts for selective oxidation of propane and derivatives: II. The relationship among catalyst preparation, structure and catalytic properties. Appl Catal A Gen 2003; 250: 287-303

[19] Manuel B, Jean-Marc M. Bulk oxidation state of the different cationic elements in the $\mathrm{MoVTe}(\mathrm{Sb}) \mathrm{NbO}$ catalysts for oxidation or ammoxidation of propane. Appl Catal A Gen 2005; 279: 67-77.

[20] Balcells E, Borgmeier F, Grißtede I, Rosowskib F. Partial oxidation of propane to acrylic acid at a Mo-V-Te-Nb-oxide catalyst. Appl Catal A 2004; 266: 211-21.

[21] Kenzo O, Tokio H, Youhei K, Wataru U. Catalytic performance of hydrothermally synthesized Mo-V-M-O $(\mathrm{M}=\mathrm{Sb}$ and $\mathrm{Te})$ oxides in the selective oxidation of light paraffins. Studies Surf Sci Catal 2001; 136: 93-8.

[22] Tokuro M, Fumimaru O, Toshitatsu M, Hiroshi U, Kazuyoshi B. Effect of a large temperature difference and pyrolysis on the heat transfer between a cylinder and transverse gas flows of nitrogen and propane. Int J Heat Mass Trans 1984; 27: 829-41.

[23] Murayama H, Vitry D, Ueda W, Fuchs G, Anne M, Dubois J. Structure characterization of orthorhombic phase in MoVTeNbO catalyst by powder X-ray diffraction and XANES. Appl Catal A Gen 2007; 318: 137-42.

[24] Carlo L, Pietro M, Fabrizio C, Michel D. Sol-Gel synthesisaand characterization of $\mathrm{Nb}-\mathrm{Mo}$ and $\mathrm{Nb}-\mathrm{Mo}-\mathrm{V}$ mixed oxides as potential catalysts for the selective oxidation of propane. Studies Surf Sci Catal 2006; 162: 841-48

[25] Novakova E, Vedrine J, Derouane E. Propane Oxidation on Mo-VSb-Nb Mixed-Oxide Catalysts: 1. Kinet Mech Studies J Catal 2002; 211: 226-34

[26] Baerns M, Buyevskaya O, Kubik M. Catalytic partial oxidation of propane to acrolein. Catal Today 1997; 33: 85-96.

[27] Li W, Oshihara K, Ueda W. Catalytic performance for propane selective oxidation and surface properties of 12molybdophosphoric acid treated with pyridine. Appl Catal A 1999; 182: 357-63.

[28] Noritaka M, Masaki T, Masakazu I. Pronounced catalytic activity of $\mathrm{Fe}_{0.08} \mathrm{Cs}_{2.5} \mathrm{H}_{1.26} \mathrm{PVMo}_{11} \mathrm{O}_{40}$ for direct oxidation of propane into acrylic acid. Appl Catal A Gen 1995; 128: L165-L70.

[29] Savary L, Saussey J, Costentin G, Bettahar M, GubelmannBonneau M, Lavalley J. Propane oxydehydrogenation reaction on a $\mathrm{VPO} / \mathrm{TiO}_{2}$ catalyst. Role of the nature of acid sites determined by dynamic in-situ IR studies. Catal Today 1996; 32: 57-61.

[30] Centi G, Marchi F, Perathoner S. Effect of ammonia chemisorption on the surface reactivity of V-Sb-oxide catalysts for propane ammoxidation. Appl Catal A Gen 1997; 149: 225-44.

[31] Savary L, Saussey J, Costentin G, Bettahar M, GubelmannBonneau M. Propane oxydehydrogenation reaction on a $\mathrm{VPO} / \mathrm{TiO}_{2}$ catalyst. Role of the nature of acid sites determined by dynamic insitu IR studies. J Catal Today 1996; 32: 57-61.

[32] Landi G, Lisi L, Volta J. Oxidation of propane to acrylic acid over vanadyl pyrophosphate: modifications of the structural and acid properties during the precursor activation and their relationship with catalytic performances. J Mol Catal A Chem 2004; 222: 17581. 